\title{
PENENTUAN LITOLOGI LAPISAN BAWAH PERMUKAAN BERDASARKAN TOMOGRAFI SEISMIK REFRAKSI UNTUK GEOTEKNIK BENDUNGAN AIR DAERAH "X"
}

\author{
Hilman Sabiq ${ }^{* 1}$, Syamsurijal Rasimeng ${ }^{1}$, Karyanto ${ }^{1}$ \\ J1 Prof. Dr. Sumantri Brojonegoro No.1 Bandar Lampung 35145 \\ Jurusan Teknik Geofisika, FT UNILA \\ e-mail:*1hilmansabiq30@gmail.com
}

\begin{abstract}
ABSTRAK
Sungai Batang Toru yang melewati Kecamatan Sipirok, Kabupaten Tapanuli Selatan merupakan aliran sungai yang akan dijadikan sebagai pembangkit listrik tenaga air, untuk memenuhi kebutuhan listrik area Sumatera Utara dan sekitarnya. Oleh karena itu, survei seismik refraksi dibutuhkan untuk mengetahui litologi bawah permukaan, sebagai pedoman dalam pembangunan bendungan air sungai pada daerah tersebut. Penelitian ini bertujuan untuk menentukan litologi di daerah penelitian berdasarkan penampang tomografi seismik refraksi, serta mengestimasikan kedalaman dan ketebalan lapisan batuan di bawah permukaan daerah penelitian. Tomografi seismik refraksi menghasilkan penampang yang menunjukkan sebaran nilai kecepatan terhadap kedalaman, sehingga diperoleh interpretasi litologi batuan dan estimasi kedalaman dari tiap lapisan. Lapisan pertama merupakan lapisan topsoil dengan rentang nilai kecepatan 100-700 m/s, ketebalan topsoil diestimasi sekitar 1-10 meter Lapisan kedua diindikasikan sebagai batuan tuff-pasiran dengan konsolidasi sedang dengan rentang nilai kecepatan 600-1800 m/s, dengan estimasi ketebalan sekitar 10-35 meter. Lapisan ketiga diindiasikan sebagai batuan tuff-pasiran hingga tuff-breksi dengan rentang nilai kecepatan lebih besar dari 1800 $\mathrm{m} / \mathrm{s}$, dengan estimasi kedalaman 30-40 meter dari permukaan.
\end{abstract}

\begin{abstract}
Batang Toru river which is through Kecamatan Sipirok, Kabupaten Tapanuli Selatan, will be a hydroelectric power plant, in order to require the electricity in North Sumatera area. Therefore, refraction seismic survey needed to determine the subsurface litology, as a guide in the construction of river water dam in that area. This study aims to determine lithology in the research area based on cross-section of refraction seismic tomography, and to estimate the depth and thickness of the rock layers beneath the surface of the study area. Refraction seismic tomography produces a cross section which shows the distribution of velocity value to depth, so we obtain the interpretation of rock lithology and depth estimation of each layer. The first layer is a topsoil layer with a velocity range of $100-700 \mathrm{~m} / \mathrm{s}$, the thickness of the topsoil is estimated to be about $1-10$ meters. The second layer is indicated as a tuff-sandstone with medium consolidation with a velocity range of $600-1800 \mathrm{~m} / \mathrm{s}$, with an estimated thickness about 10-35 meters. The third layer is indicated as a tuff-sand rock to tuff-breccia with a value range higher than $1800 \mathrm{~m} / \mathrm{s}$, with an estimated depth of 30-40 meters from the surface.
\end{abstract}

Keywords-water dam, refraction seismic, tomography

\section{PENDAHULUAN}

Sungai Batang Toru merupakan sungai yang memiliki potensi untuk dijadikan pembangkit listrik tenaga air (PLTA). Bendungan air diperlukan dalam pembangunan PLTA untuk menghasilkan energi listrik yang diperlukan. Oleh karena itu akan dibangun bendungan di aliran sungai Batang Toru, salah satunya terletak di araea Kecamatan Sipirok. Maka dilakukan uji seismik refraksi pada daerah 
aliran sungai tersebut untuk mengetahui perlapisan tanah dasar sesuai dengan Pedoman Penyelidikan Geoteknik untuk Fondasi Bangunan Air (Kemeterian PU, 2005). Dengan menentukan waktu tiba gelombang seismik (two-way-time) maka kecepatan rambat gelombang seismik (v) pada setiap medium batuan dapat diketahui. Nilai kecepatan rambat gelombang seismik inilah yang akan memberikan informasi lapisan batuan bawah permukaan. Penelitian yang dilakukan ini menggunakan metode seismik refraksi untuk melihat respon bawah permukaan terhadap sumber gelombang seismik, kemudian diperoleh nilai kecepatan rambat gelombang, sehingga diperoleh informasi tentang litologi bawah permukaan daerah penelitian.

\section{TINJAUAN PUSTAKA}

\subsection{Lokasi Daerah Penelitian}

Daerah penelitian ini berada di Kecamatan Batang Toru, Kabupaten Tapanuli Selatan, Sumatera Utara.

\subsection{Geologi Regional}

Secara regional di daerah Sumatera Utara tersingkap barbagai macam batuan mulai dari batuan sedimen, beku, metasedimen hingga malihan yang berumur Karbon hingga umur Pleistosen. Batuan intrusif tua yang berumur Kapur hingga Tersier, baik jenis granodiorit maupun granit porfiri yang terdapat di daerah Padang Sidempuan sampai daerah selatan Solok, Sumatera Barat dan juga di bagian timur hingga barat daerah Sibolga. Batuan intrusif tua dan malihan berumur pra-Tersier menjadi basement dari cekungan-cekunag sedimen di sepanjang jalur belakang busur vulkanik. Batuan vulkanik banyak tersingkap di bagian tengah yang merupakan jalur vulkanik aktif sejak Oligosen Atas hingga Resen yang dicirikan oleh banyaknya kerucutkerucut gunungapi aktif seperti Sibayak, Sinabung, Sarula, Sorik Marapi, dan sebagainya, komposisi batuan vulkanik di sepanjang jalur ini bervariasi dari mulai basaltik hingga riolitik. Piroklastik Toba merupakan produk yang paling besar volume dan luas areal penyebarannya dari sekian banyak produk vulkanik di daerah Sumatera Utara. Kawasan Batang Toru, seperti yang ditampilkan pada Gambar 1, berada di daerah vulkanis aktif, dimana kawasan ini merupakan bagian dari rangkaian Pegunungan Bukit Barisan dan juga merupakan bagian dari Daerah Patahan Besar Sumatera (Great Sumatran Fault Zone) atau secara spesifik dikenal sebagai Sub Patahan Batang Gadis-Batang Angkola-Batang Toru. Patahan ini terus bergerak, sehingga kerap kali menimbukan gempabumi besar seperti yang terjadi di Sarulla (1984), Tarutung (1987), Padangsidempuan, Mandailing Natal (2006) dan Pahae (2008).

\subsection{Fisiografi}

Pulau Sumatera memiliki luas daerah berkisar $435.000 \mathrm{~km} 2$, dengan panjang $1650 \mathrm{~km}$, lebar 100-200 km di daerah utara dan $350 \mathrm{~km}$ di daerah selatan. Menurut van Bemmelen (1949), zona fisiografi Sumatera bagian utara dibagi atas 5 bagian, yaitu: a. Blok pegunungan struktur b. Jalur depresi/graben c. Embayment Meulaboh dan Singkil d. Kaki perbukitan dan dataran rendah e. Kompleks gunung api muda Zona fisiografi blok pegunungan struktur dan jalur depresi/graben mencakup hampir seluruh Pulau Sumatera, didominasi oleh batuan berumur PraTersier hingga Tersier Awal. Jalur depresi (graben) mencakup daerah tengah Sumatera memanjang utara-selatan, didominasi oleh batuan berumur PraTersier hingga Tersier Awal. Zona embayment Meulaboh dan Singkil mencakup daerah pantai barat, didominasi oleh batuan 
berumur Tersier Awal hingga Kuarter.

\section{TEORI DASAR}

\subsection{Seismik Refraksi}

Metode seismik refraksi yang diukur adalah waktu tempuh gelombang dari sumber menuju geophone. Berdasarkan bentuk kurva waktu tempuh terhadap jarak, dapat ditafsirkan kondisi batuan di daerah penelitian. Pada (Tabel 1 dan Tabel 2) menunjukkan data kecepatan gelombang primer pada beberapa medium. Seismik refraksi dihitung berdasarkan waktu yang dibutuhkan oleh gelombang untuk menjalar pada batuan dari posisi sumber seismik menuju penerima pada berbagai jarak tertentu. Pada metode ini, gelombang yang terjadi setelah sinyal pertama (firstbreak) diabaikan, karena gelombang seismik refraksi merambat paling cepat dibandingkan dengan gelombang lainnya kecuali pada jarak (offset) yang relatif dekat sehingga yang dibutuhkan adalah waktu pertama kali gelombang diterima oleh setiap geophone. Kecepatan gelombang $\mathrm{P}$ lebih besar dibandingkan dengan kecepatan gelombang $\mathrm{S}$ sehingga waktu datang gelombang $\mathrm{P}$ yang digunakan dalam perhitungan metode ini. Parameter jarak dan waktu penjalaran gelombang dihubungkan dengan cepat rambat gelombang dalam medium. 3.2. Interpretasi Data Seismik Refraksi Secara umum metode interpretasi data seismik refraksi dapat dikelompokkan menjadi tiga kelompok utama, yaitu intercept time, delay time method dan wave front method. Metode interpretasi yang paling mendasar dalam analisis data seismik refraksi adalah intercept time. Metode intercept time adalah metode T-X (waktu terhadap jarak) yang merupakan metode yang paling sederhana dan hasilnya cukup kasar, seperti yang ditunjukkan pada Gambar 2 Kedalaman lapisan pertama dapat dihitung menggunakan persamaan

$$
Z_{1}=\frac{T_{i} V_{1}}{2 \cos \alpha}
$$

Untuk kedalaman lapisan kedua akan diperoleh suatu persamaan

$$
Z_{2}=\left[T_{i 2}-\frac{2 Z_{1}^{-}}{V_{1} V_{3}} \sqrt{\left(V_{2}\right)^{2}-\left(V_{1}\right)^{2}}\right] \frac{V_{3} V_{8}}{2 \sqrt{\left(V_{3}\right)^{2}+\left(V_{2}\right)^{2}}}
$$

Maka, Dengan menggunakan intercept time dan jarak kritis (x) dapat diketahui kedalaman interface untuk sejumlah $n$ refraktor data

$Z_{n}=\frac{v_{n}}{2 \cos \theta_{n}}\left(t_{n}-\sum_{i}^{n-1} \frac{2 Z_{i} \cos \theta_{i}}{v_{i}}\right)$

\subsection{Tomografi Seismik}

Refraksi Metode refraksi tomografi ini diawali dengan pembuatan kecepatan awal dan kemudian dilakukan iterasi pelacakan sinar (forward refraction raytracing) melalui pemodelan, kemudian membandingkan waktu tempuh perhitungan dengan waktu tempuh pengukuran, memodifikasi model, dan mengulangi proses sampai waktu perhitungan dan pengukuran mencapai nilai minimal. Tujuan utamanya adalah menemukan waktu tempuh minimum antara sumber dan penerima untuk setiap pasangan sumber-penerima. Hal ini dicapai dengan pemecahan 1 (raypath) dan $S$ (slowness). Iterasi yang digunakan adalah pendekatan non linear least-square.

$$
S=\frac{l}{v}
$$

dengan $\mathrm{S}=$ slowness

$1=$ raypath

$\mathrm{v}=$ kecepatan gelombang $\mathrm{P}$

\section{METODE PENELITIAN}

\subsection{Perangkat dan Data Penelitian}

Perangkat yang digunakan dalam penelitian ini adalah Software Reflexw yang terdiri dari:

1. 2D Analysis, untuk melakukan input Raw Data dan melakukan picking first 
break.

2. Traveltime Analysis, untuk melakukan pemilihan waktu tempuh.

3. Modelling, untuk melakukan proses inversi waktu tempuh dan tomografi kecepatan.

Sedangkan data yang digunakan dalam adalah

1. Data seismik dengan format SEG-2 yang berjumlah 10 line dengan bentangan 30 dan 40 geophone..

2. Data topografi berupa elevasi dari setiap shot dan geophone yang diukur menggunakan GPS

3. Data geologi regional digunakan untuk mengetahui gambaran geologi pada daerah penelitian.

\subsection{Tahapan Pengolahan}

1. Reformatting adalah tahap pengubahan format data seismik dari SEG-2 menjadi format .dat, untuk mengimport data pada software Reflexw menggunakan menu import.

2. Tahapan muting dilakukan untuk memperjelas amplitudo terutama pada bagian atas untuk mempermudah dalam pemilihan gelombang tiba pertama (first break), sedangkan tahap filtering dilakukan untuk memilih frekuensi seismik yang akan dilakukan pengolahan selanjutnya

3. Setelah melakukan filtering, maka tahap selanjutnya melakukan First break picking dengan cara memilih gelombang seismik yang pertama kali sampai ke receiver.

4. Traveltime Inversion dilakukan dengan cara menginversi waktu tempuh penjalaran gelombang yang diperoleh dari tahap traveltime picking. Dalam tahap ini dilakukan inversi least square dengan metode regresi linear.

5. Tahapan akhir adalah pemodelan tomografi yang bertujuan untuk menyajikan gambaran bawah permukaan dengan domain kecepatan hasil dari inversi waktu tempuh gelombang seismik refraksi. Pemodelan ini dilakukan dengan metode intercept time.

\section{HASIL DAN PEMBAHASAN}

\subsection{Geometri Pengukuran Lapangan}

Survei seismik refraksi di area Batang Toru, Kabupaten Tapanuli Selatan meliputi 4 line seismik refraksi dengan arah sejajar sungai Batang Toru, dan 6 line seismik dengan arah tegak lurus sungai Batang Toru. Empat line seismik dengan arah sejajar dengan sungai, yaitu BTD-D4, BTD-D5, BTD-D6, dan BTD-D7. Sedangkan line seismik dengan arah tegak lurus sungai, yaitu BTD-D1A, BTD-D1B, BTD-D2A， BTD-D2B， BTD-D3A， dan BTD-D3B.

\subsection{Analisis dan Interpretasi}

Model penampang seismik line BTD1A (Gambar 3) hasil tomografi memperlihatkan sebaran nilai kecepatan gelombang $\mathrm{P}(\mathrm{Vp})$ terbagi menjadi tiga rentang nilai, yang diasumsikan sebagai tiga perlapisan. Lapisan pertama dengan rentang nilai kecepatan 100-700 m/s (biru) sebagai lapisan topsoil (Tabel 1.) dengan ketebalan 5-10 meter. Lapisan kedua dengan rentang nilai kecepatan 700-1800 $\mathrm{m} / \mathrm{s}$ (hijau-kuning) diindikasikan sebagai batuan tuff-pasiran berdasarkan data coring BTD-12, ditemukan hingga kedalaman 4060 meter. Lapisan ketiga dengan rentang nilai kecepatan lebih besar dari $1800 \mathrm{~m} / \mathrm{s}$ (merah hingga ungu) diindikasikan sebagai batuan tuff-pasiran hingga tuff-breksi yang telah terkonsolidasi sangat baik sehingga nilai kecepatannya lebih besar dibandingkan dengan lapisan di bagian atasnya Pada model penampang seismik line BTD-D1B (Gambar 4) hasil tomografi, lapisan pertama dengan rentang nilai kecepatan 100-700 m/s (biru) sebagai lapisan topsoil (Tabel 1) dengan estimasi ketebalan 2-7 meter. Lapisan kedua dengan 
rentang nilai kecepatan 700-1800 m/s (hijau-kuning) diindikasikan sebagai batuan tuff-pasiran ditemukan hingga kedalaman 7-20 meter.

Lapisan ketiga dengan rentang nilai kecepatan lebih besar dari $1800 \mathrm{~m} / \mathrm{s}$ (merah hingga ungu) diindikasikan sebagai batuan tuff-pasiran hingga tuff-breksi. Pada model penampang seismik line BTDD2A (Gambar 5) hasil tomografi, lapisan pertama dengan rentang nilai kecepatan $100-600 \mathrm{~m} / \mathrm{s}$ (biru) sebagai lapisan topsoil (Tabel 1) dengan estimasi ketebalan 1-10 meter. Lapisan kedua dengan rentang nilai kecepatan 600-1800 m/s (hijau-kuning) diindikasikan sebagai batuan tuff-pasiran dengan konsolidasi sedang hingga kedalaman 5-20 meter. Lapisan ketiga dengan rentang nilai kecepatan lebih besar dari $1800 \mathrm{~m} / \mathrm{s}$ (merah-ungu) diindikasikan sebagai batuan tuff-pasiran hingga tuffbreksi.

Pada model penampang seismik line BTD-D2B (Gambar 6) hasil tomografi, lapisan pertama dengan rentang nilai kecepatan 100-700 m/s (biru) sebagai lapisan topsoil (Tabel 1) dengan ketebalan 5-10 meter. Lapisan kedua dengan rentang nilai kecepatan 700-1800 $\mathrm{m} / \mathrm{s}$ (hijaukuning) diindikasikan sebagai batuan tuffpasiran ditemukan pada kedalaman 1020 meter. Lapisan ketiga dengan rentang nilai kecepatan lebih besar dari $1800 \mathrm{~m} / \mathrm{s}$ (merah-ungu) diindikasikan sebagai batuan tuff-pasiran hingga tuff-breksi. Pada model penampang seismik line BTD-D3A (Gambar 7) hasil tomografi, lapisan topsoil relatif merata dengan ketebalan ketebalan 8-10 meter. Lapisan kedua dengan rentang nilai kecepatan 700-1800 m/s (hijau, kuning, hingga merah muda) diindikasikan sebagai batuan tuff-pasiran (Tabel 2) dengan konsolidasi sedang pada kedalaman 10-20 meter.

Lapisan ketiga dengan rentang nilai kecepatan lebih besar dari $1800 \mathrm{~m} / \mathrm{s}$ (merah hingga ungu) diindikasikan sebagai batuan tuff-pasiran hingga tuff-breksi. Pada model penampang seismik line BTD-
D3B (Gambar 8) hasil tomografi, lapisan pertama dengan rentang nilai kecepatan $100-700 \mathrm{~m} / \mathrm{s}$ (biru) sebagai lapisan topsoil dengan ketebalan 5-10 meter. Lapisan kedua dengan rentang nilai kecepatan 700$1800 \mathrm{~m} / \mathrm{s}$ (hijau, kuning hingga merah muda) diindikasikan sebagai batuan tuffpasiran dengan konsolidasi sedang pada kedalaman 10-20 meter.

Lapisan ketiga dengan rentang nilai kecepatan lebih besar dari $1800 \mathrm{~m} / \mathrm{s}$ (merah hingga ungu) diindikasikan sebagai batuan tuff-pasiran hingga tuff-breksi. Pada model penampang seismik line BTDD4 (Gambar 9) hasil tomografi, lapisan pertama dengan rentang nilai kecepatan $100-700 \mathrm{~m} / \mathrm{s}$ (biru) sebagai lapisan topsoil dengan ketebalan bervariasi 10-25 meter. Lapisan kedua dengan rentang nilai kecepatan 700-1800 m/s (hijau) diindikasikan sebagai batuan tuffpasiran dengan konsolidasi sedang pada kedalaman 15-40 meter. Lapisan ketiga dengan rentang nilai kecepatan lebih besar dari $1800 \mathrm{~m} / \mathrm{s}$ (kuning, merah hingga ungu) diindikasikan sebagai batuan tuffpasiran hingga tuff-breksi. Pada model penampang seismik line BTD-D5 (Gambar 10) hasil tomografi, lapisan pertama dengan rentang nilai kecepatan 100-500 $\mathrm{m} / \mathrm{s}$ (biru) sebagai lapisan topsoil dengan ketebalan bervariasi 10-15 meter.

Lapisan kedua dengan rentang nilai kecepatan 600-1500 m/s (hijau-kuning) diindikasikan sebagai batuan tuff-pasiran dengan konsolidasi sedang pada kedalaman 15-25 meter. Lapisan ketiga dengan rentang nilai kecepatan lebih besar dari $1500 \mathrm{~m} / \mathrm{s}$ (kuning, merah hingga ungu) diindikasikan sebagai batuan tuffpasiran hingga tuffbreksi. Pada model penampang seismik line BTD-D6 (Gambar 11) hasil tomografi, lapisan pertama dengan rentang nilai kecepatan 100-700 $\mathrm{m} / \mathrm{s}$ (biru) sebagai lapisan topsoil dengan ketebalan relatif kecil yaitu sekitar 3-6 meter. Lapisan kedua dengan rentang nilai kecepatan 1000-1500 m/s (hijau-kuning) diindikasikan sebagai batuan tuff-pasiran 
dengan konsolidasi sedang pada kedalaman 8-30 meter. Lapisan ketiga dengan rentang nilai kecepatan lebih besar dari $1500 \mathrm{~m} / \mathrm{s}$ (kuning, merah hingga ungu) diindikasikan sebagai batuan tuffpasiran hingga tuff-breksi. Pada model penampang seismik line BTD-D7 (Gambar 12) hasil tomografi, lapisan pertama dengan rentang nilai kecepatan 100-700 $\mathrm{m} / \mathrm{s}$ (biru) sebagai lapisan topsoil dengan ketebalan relatif kecil yaitu sekitar 1-4 meter. Lapisan kedua dengan rentang nilai kecepatan 1000-1500 m/s (hijau-kuning) diindikasikan sebagai batuan tuff-pasiran dengan konsolidasi sedang pada kedalaman 8-35 meter.

Lapisan ketiga dengan rentang nilai kecepatan lebih besar dari $1500 \mathrm{~m} / \mathrm{s}$ (merah hingga ungu) diindikasikan sebagai batuan tuff-pasiran hingga tuff-breksi. Hasil interpretasi penampang tomografi seismik refraksi mengindikasikan pada lapisan pertama merupakan topsoil dengan rentang nilai kecepatan yang relatif rendah. Lapisan ini merupakan weathering zone (zona lapuk). Lapisan kedua diindikasikan batuan tuffpasiran dengan nilai kecepatan yg lebih tinggi dibandingkan topsoil. Hal ini menunjukkan lapisan kedua ini memiliki kekerasan batuan yang lebih besar. Selanjutnya, lapisan ketiga diindikasikan sebagai batuan tuff-pasiran hingga tuffbreksi dengan nilai kecepatan yang lebih tinggi dari lapisan di atasnya. Hal tersebut mengindikasikan bahwa lapisan ini merupakan lapisan keras.

\section{KESIMPULAN DAN SARAN}

\subsection{Kesimpulan}

Adapun kesimpulan yang diperoleh dari hasil penelitian ini sebagai berikut:

1. Hasil penampang tomografi menunjukkan pada daerah penelitian diinterpretasikan terdiri dari tiga lapisan berdasarkan nilai kecepatan gelombang seismik refraksi. Tiga lapisan tersebut terdiri dari:

a. Lapisan pertama merupakan lapisan topsoil dengan rentang nilai kecepatan 100-700 m/s.

b. Lapisan kedua diindikasikan sebagai batuan tuff-pasiran dengan konsolidasi sedang dengan rentang nilai kecepatan $600-1800 \mathrm{~m} / \mathrm{s}$.

c. Lapisan ketiga diindiasikan sebagai batuan tuff-pasiran hingga tuffbreksi dengan rentang nilai kecepatan lebih besar dari 1800 $\mathrm{m} / \mathrm{s}$.

2. Berdasarkan penampang tomografi, ketebalan topsoil diestimasi sekitar 110 meter. Lapisan dibawah top soil dapat diindikasikan sebagai batuan tuffpasiran dengan konsolidasi sedang, dengan estimasi ketebalan sekitar 1035 meter. Lapisan ketiga dapat diindikasikan sebagai batuan tuffpasiran hingga tuffbreksi yang terkonsolidasi sangat baik, dengan estimasi kedalaman 30-40 meter dari permukaan.

\subsection{Saran}

1. Dibutuhkan survey lanjutan dengan metode geofisika lainnya seperti MASW dan HVSR, untuk mengetahui lebih lanjut karakterisasi batuan di daerah penelitian.

2. Direkomendasikan untuk menggunakan rekayasa geoteknik dalam pendirian bangunan air agar dapat meminimalisir resiko bahaya.

\section{UCAPAN TERIMA KASIH}

Penulis mengucapkan terima kasih kepada Syamsurijal Rasimeng, S.Si., M.T dan Karyanto, S.Si., M.T yang telah memberikan bimbingan dan memberikan dukungan terhadap penyelesaian penelitian ini. 


\section{DAFTAR PUSTAKA}

Bemmelen, R.W. van. 1949. The Geology of Indonesia Vol. IA; General Geology of Indonesia and Adjacent Archipelago. Bandung: Ditjen Geologi

Burger, H.R. 1992. Exploration geophysics of the Shallow Subsurface. Prentice Hall P T R.

Christensen, N. I., 1984. Seismic velocities. In: R. S. Carmichael (Ed.), Handbook of physical properties of rocks, Vol. 2 . CRC Press, Boca Raton, Florida.

Departemen Pertambangan dan Energi, 1982. Peta Geologi Lembar 0717 Padangsidempuan dan Lembar 0617 Sibolga.

Press, F., 1966. Seismic velocities. In: S. P. Clark, Jr. (Ed.), Handbook of physical constants . Geol. Soc.

Sismanto. 1999. Eksplorasi dengan Menggunakan Seismik Refraksi. Yogyakarta. Gajah Mada University Press.

Susilawati. 2004. Seismik Refraksi (Dasar Teori dan Akuisisi Data)., FMIPA Jurusan Fisika USU. 


\section{LAMPIRAN}

Tabel 1. Analisis Tuning Thickness

Tabel 1. Data Kecepatan Gelombang Primer Pada Beberapa Medium (Burger, 1992).

\begin{tabular}{|c|c|}
\hline Material & Kecepatan gelombang $\mathbf{P}(\mathbf{m} / \mathbf{s})$ \\
\hline Weathered layered & $200-900$ \\
\hline Soil & $250-600$ \\
\hline Clay & $1000-2500$ \\
\hline Sandstone & $3000-4500$ \\
\hline Limestone & $5500-6000$ \\
\hline Granite & $5000-5100$ \\
\hline
\end{tabular}

Tabel 2. Nilai kecepatan gelombang seismik batuan vulkanik (Press (1966); Christensen (1984); Gardner and House (1987.))

\begin{tabular}{|l|c|c|}
\hline \multirow{2}{*}{\multicolumn{1}{c|}{ Rock Type }} & $\mathbf{V p}$ & $\mathbf{V s}$ \\
\cline { 2 - 3 } & $\mathbf{( k m / s )}$ & $\mathbf{( k m} / \mathbf{s})$ \\
\hline Tuff & 1.43 & 0.87 \\
\hline Silicic Tuff & 2.16 & 0.83 \\
\hline Rhyolite & 3.27 & 1.98 \\
\hline Latite & 3.77 & 2.21 \\
\hline Volcanic Breccia & 4.22 & 2.49 \\
\hline Trachyte & 5.41 & 3.05 \\
\hline Andesite & 5.23 & 3.06 \\
\hline \multirow{4}{*}{ Basalt } & 3.35 & 1.64 \\
\cline { 2 - 3 } & 4.76 & 2.19 \\
\cline { 2 - 3 } & 5.06 & 2.72 \\
\cline { 2 - 3 } & 5.41 & 3.21 \\
\cline { 2 - 3 } & 6.4 & 3.2 \\
\hline Basaltic Scoria & 4.33 & 2.51 \\
\hline
\end{tabular}




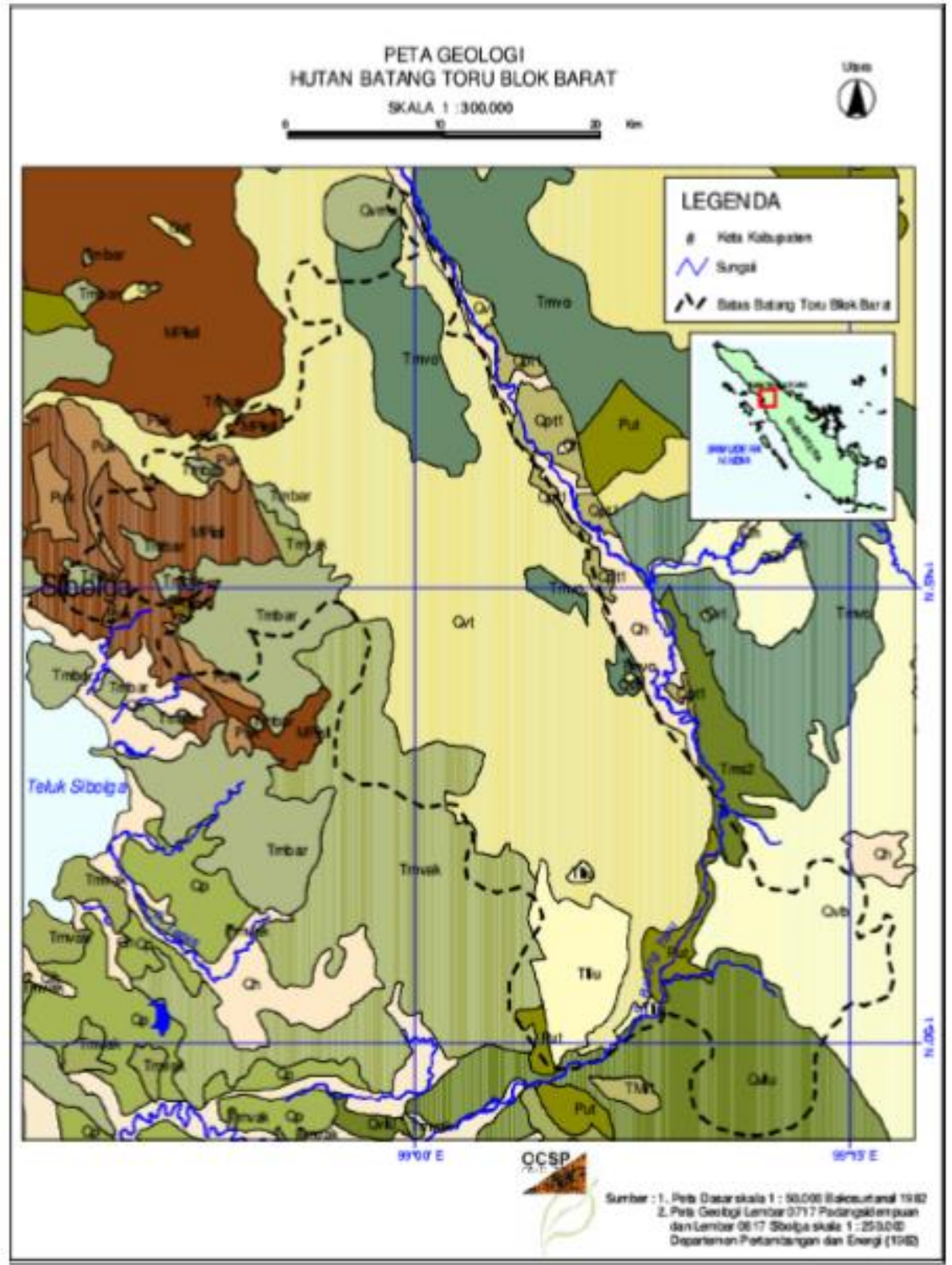

Gambar 1. Peta Geologi Batang Toru (Dep. Pertambangan dan Energi, 1982)

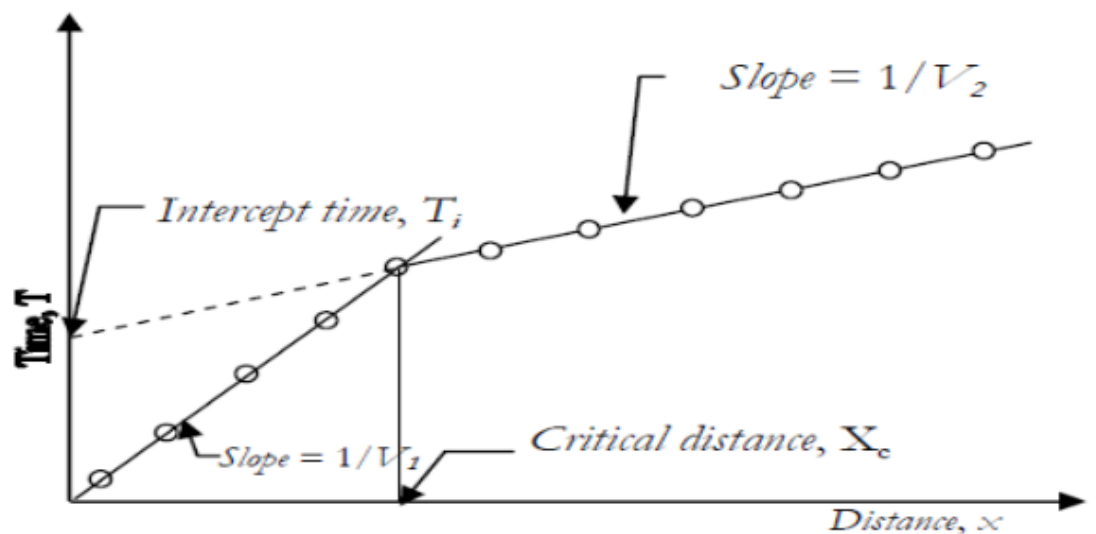

Gambar 2. Kurva travel time pada dua lapis sederhana dengan bidang batas paralel (Sismanto,1999) 


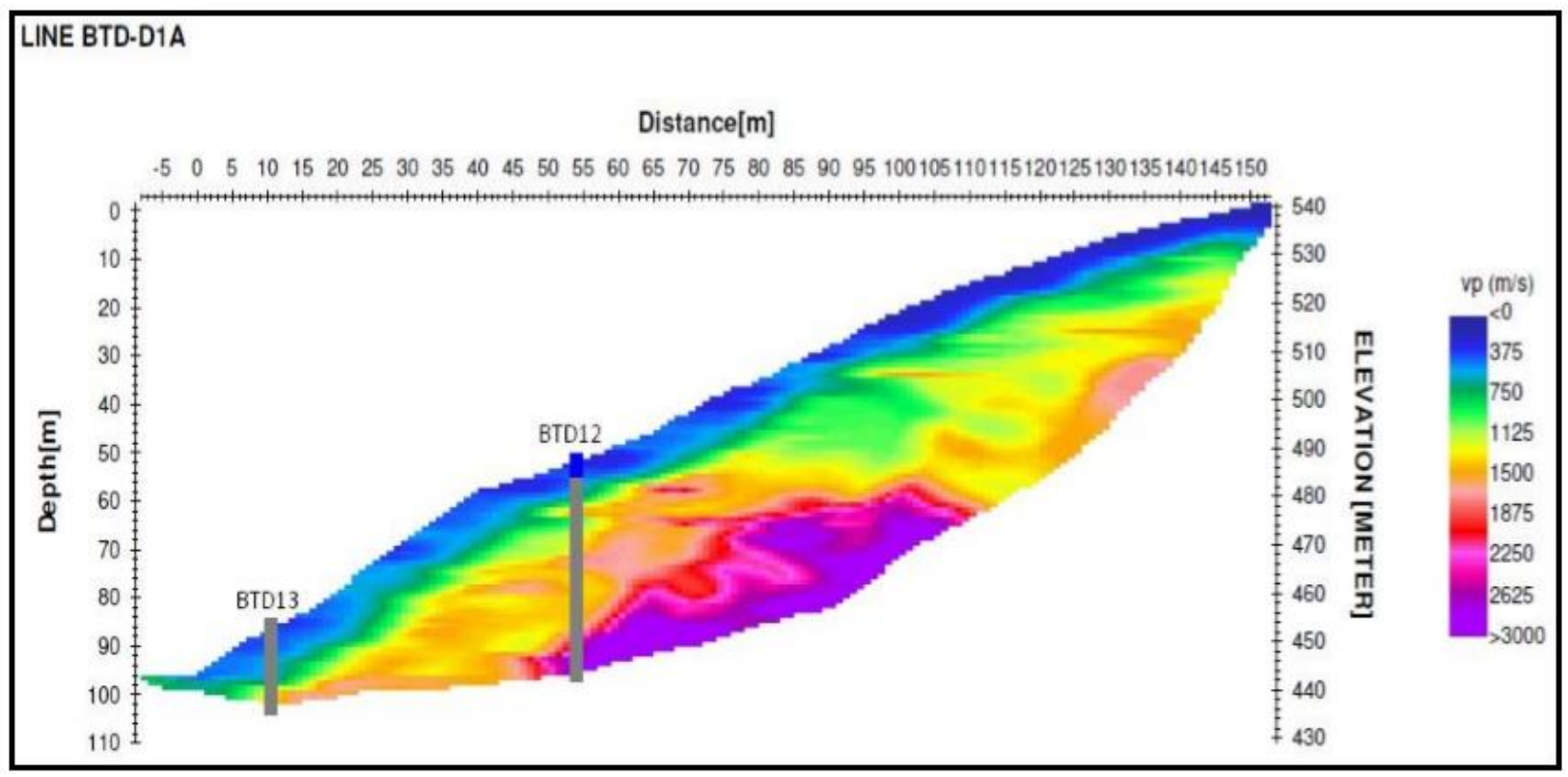

Gambar 3. Penampang seismik line BTD-D1A

LINE BTD-D1B

Distance[m]

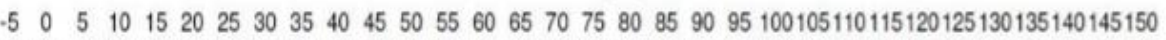

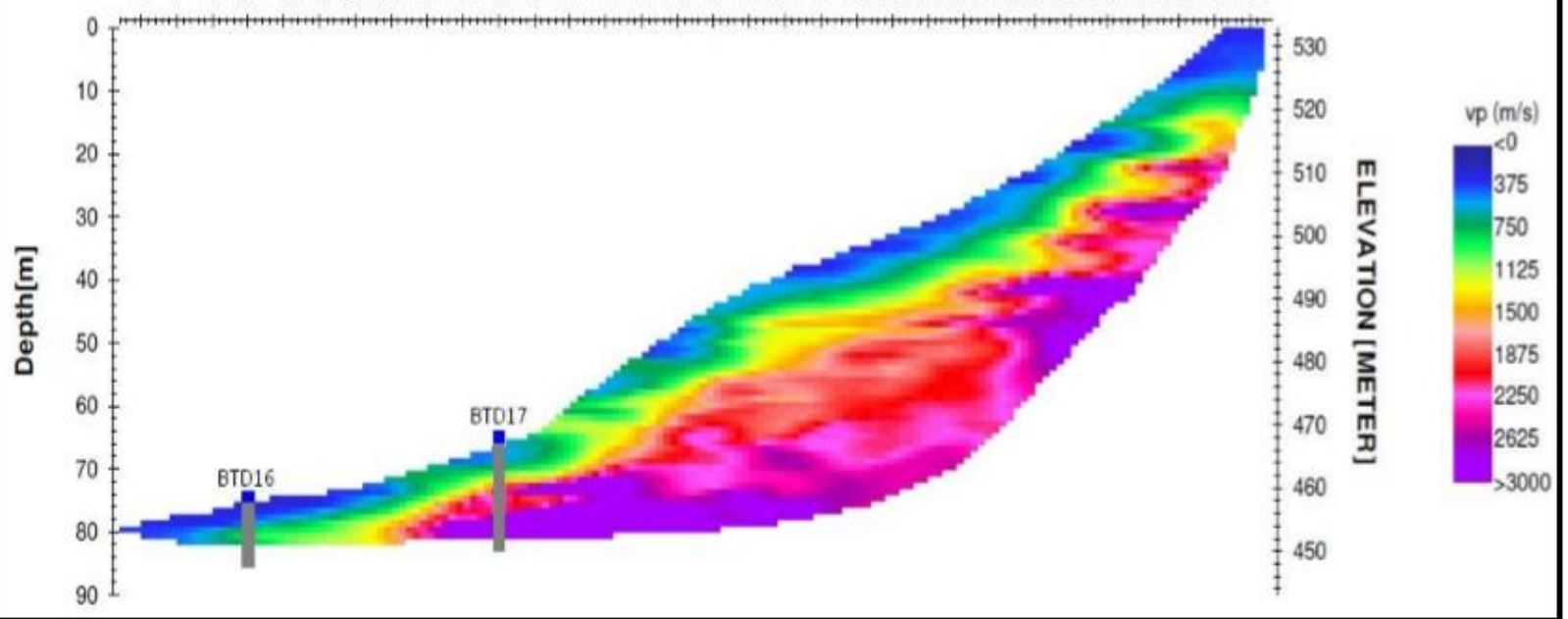

Gambar 4. Penampang seismik line BTD-D1B 


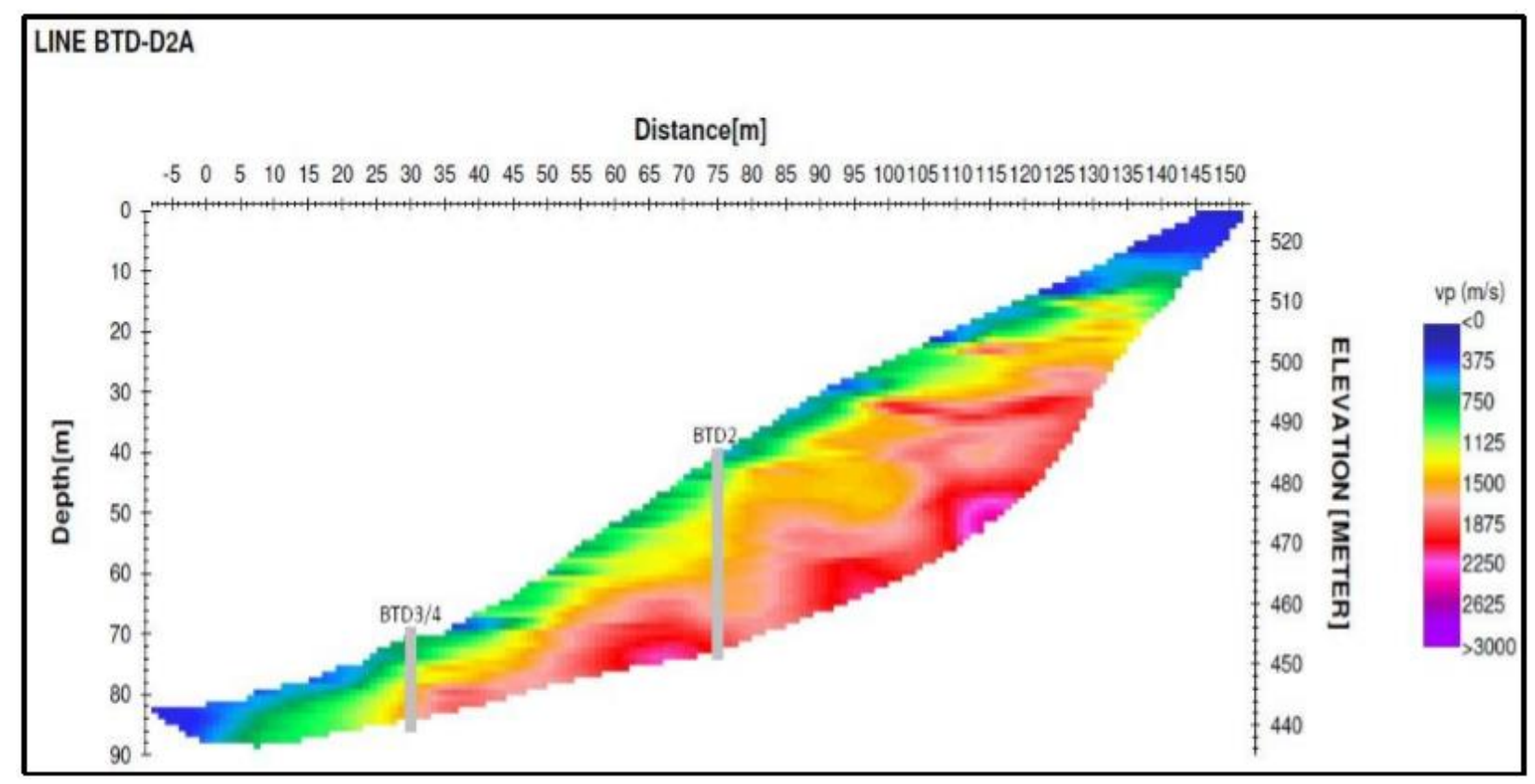

Gambar 5. Penampang seismik line BTD-D2A

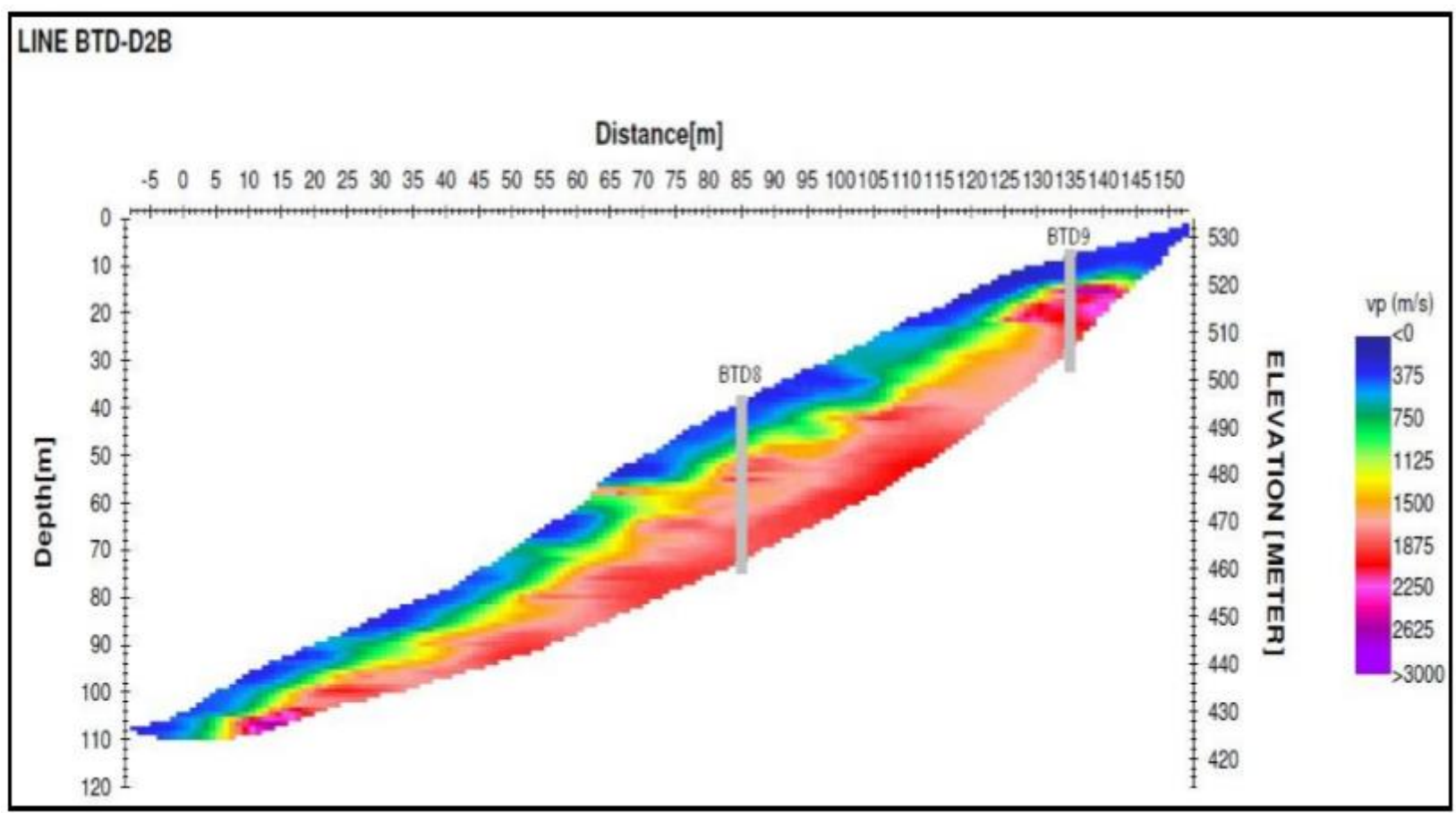

Gambar 6. Penampang seismik line BTD-D2B 


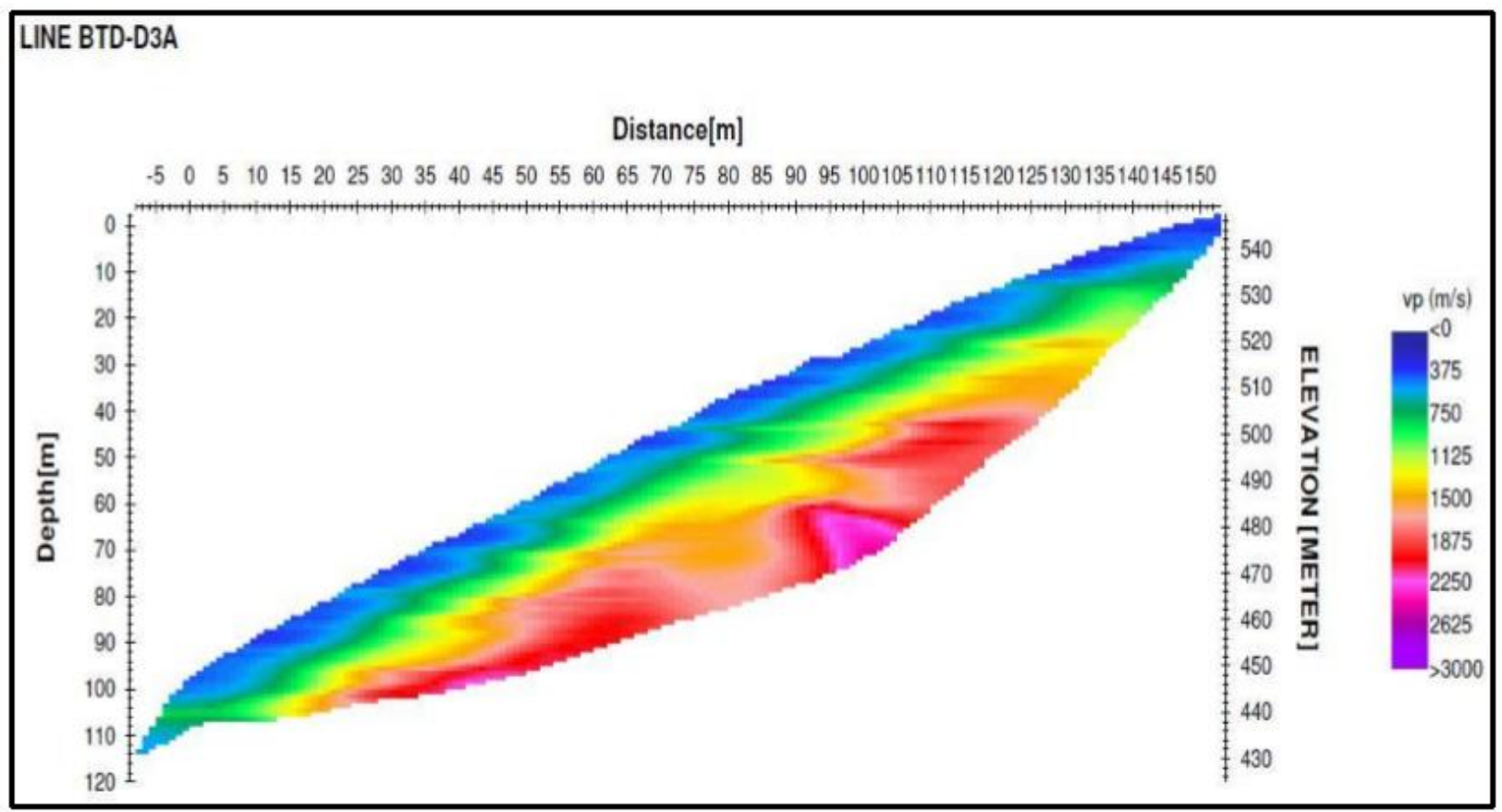

Gambar 7. Penampang seismik line BTD-D3A

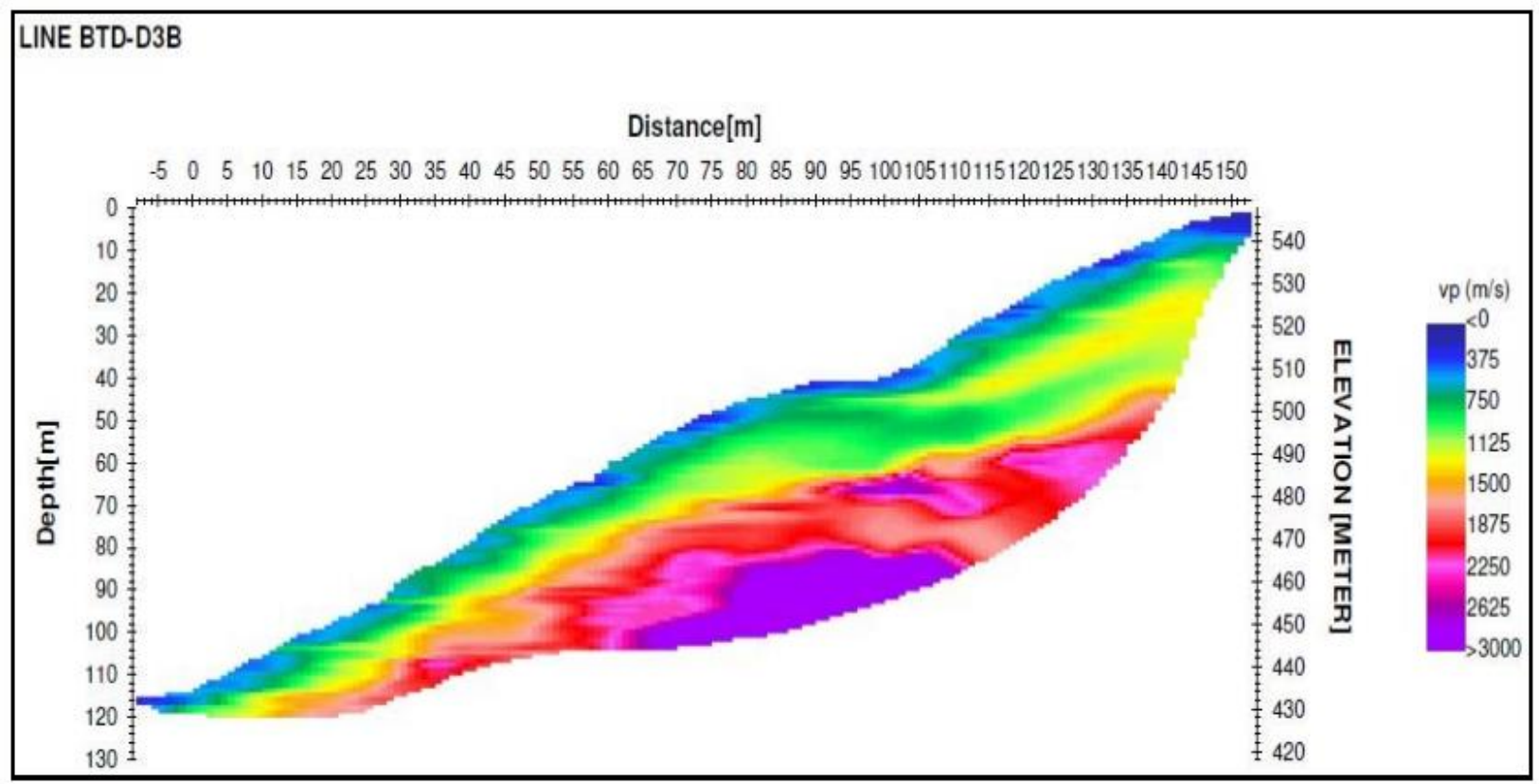

Gambar 8. Penampang seismik line BTD-D3B 


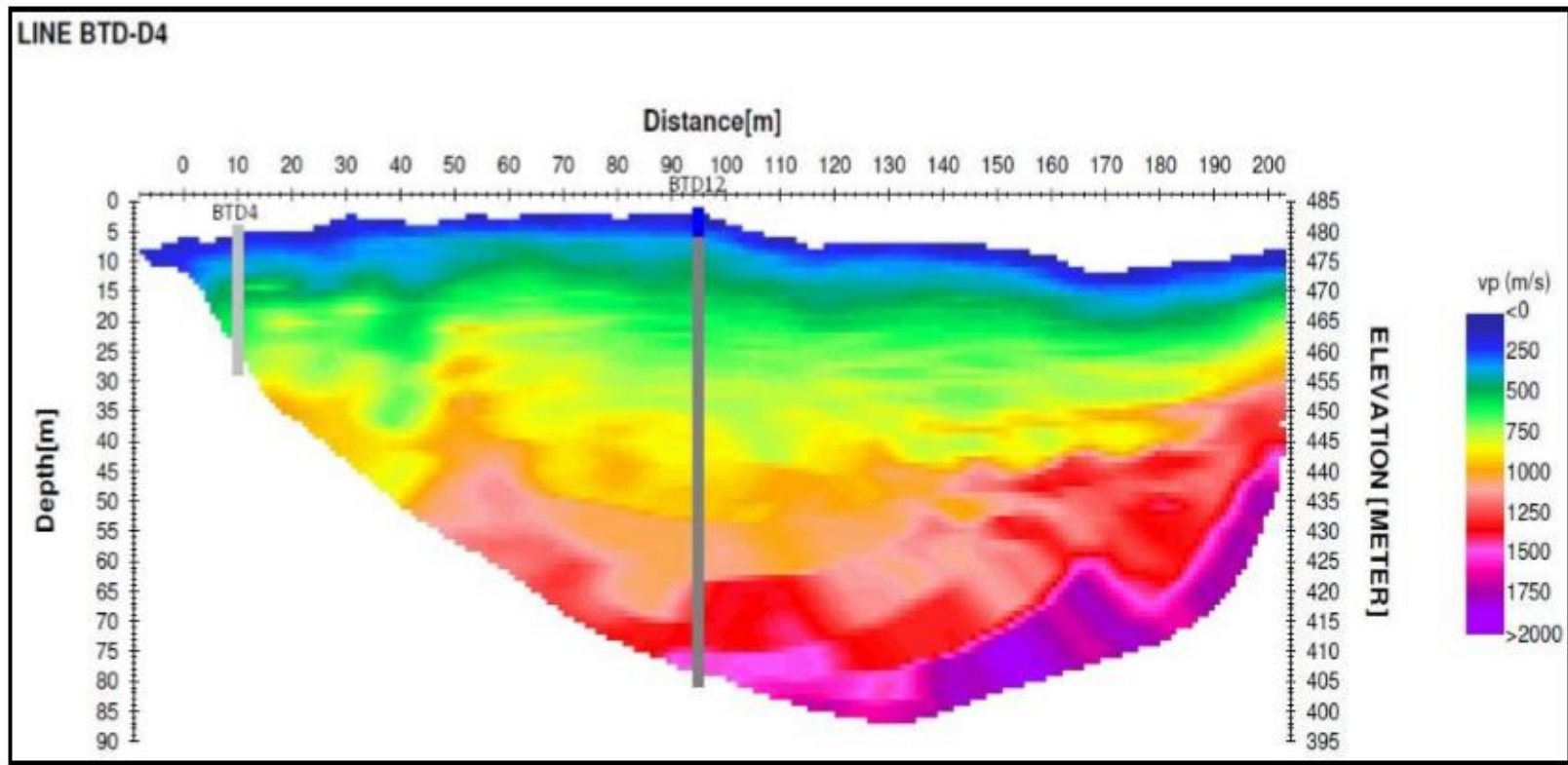

Gambar 9. Penampang seismik line BTD-D4

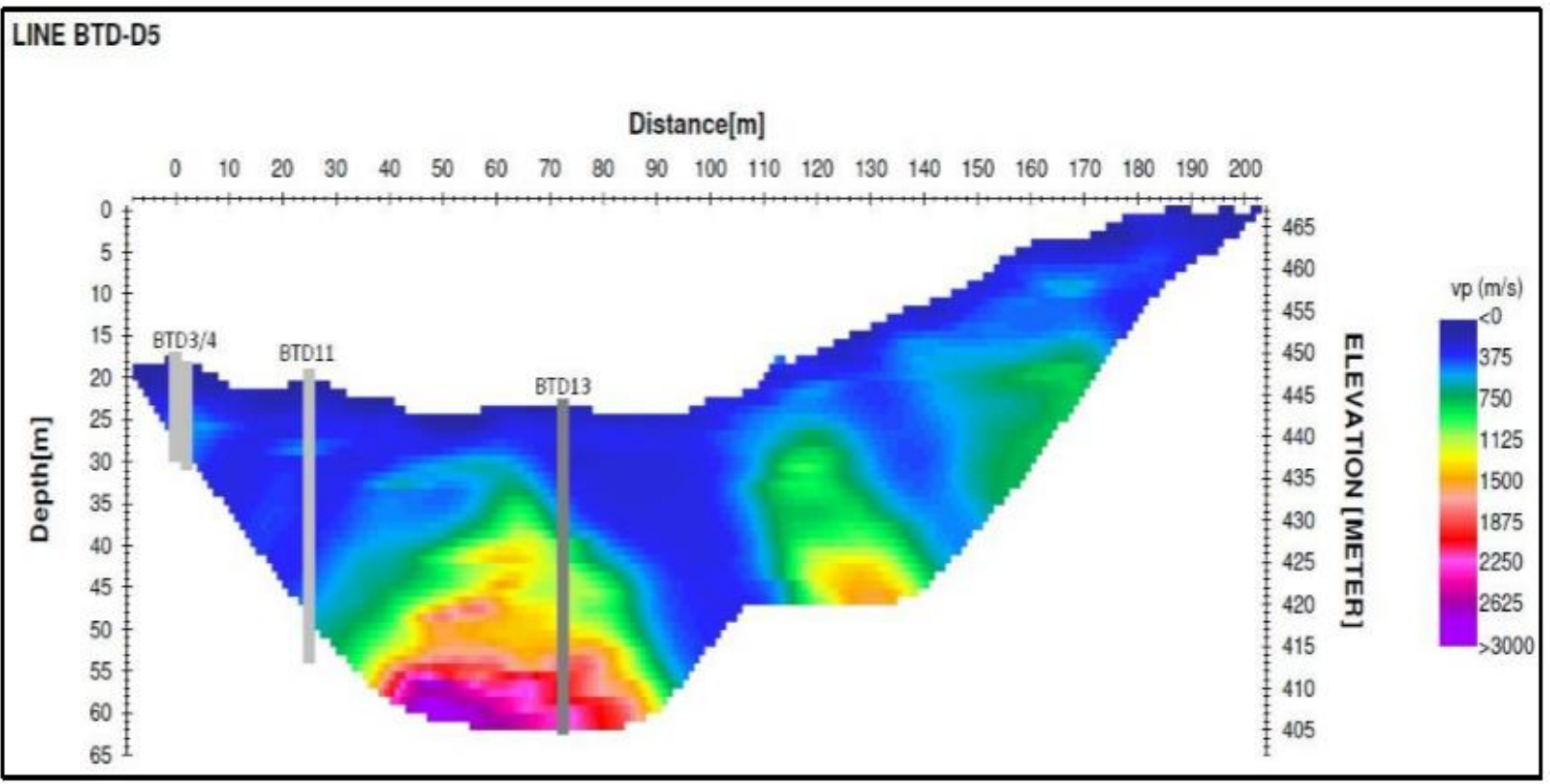

Gambar 10. Penampang seismik line BTD-D5 


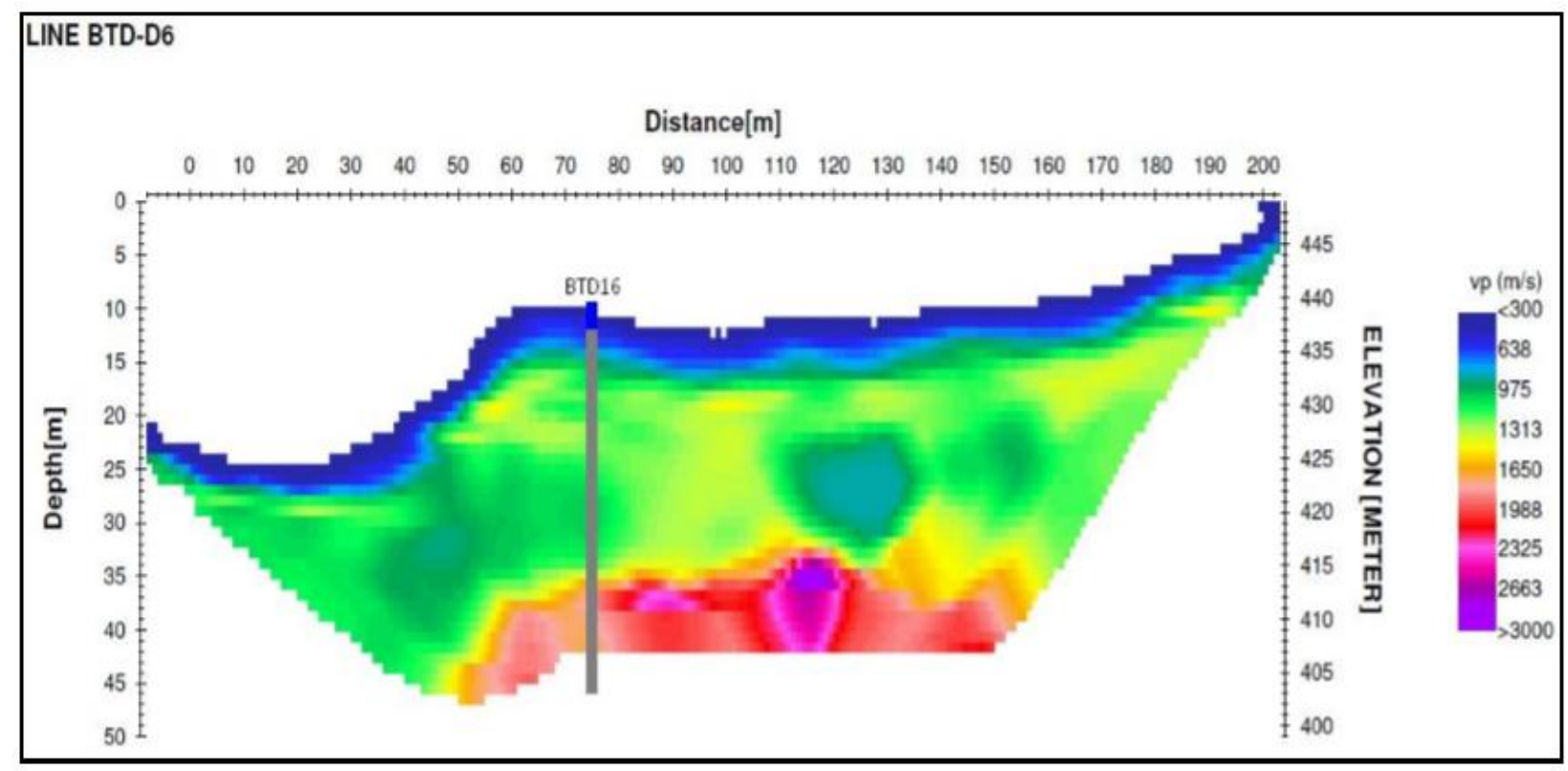

Gambar 11. Penampang seismik line BTD-D6

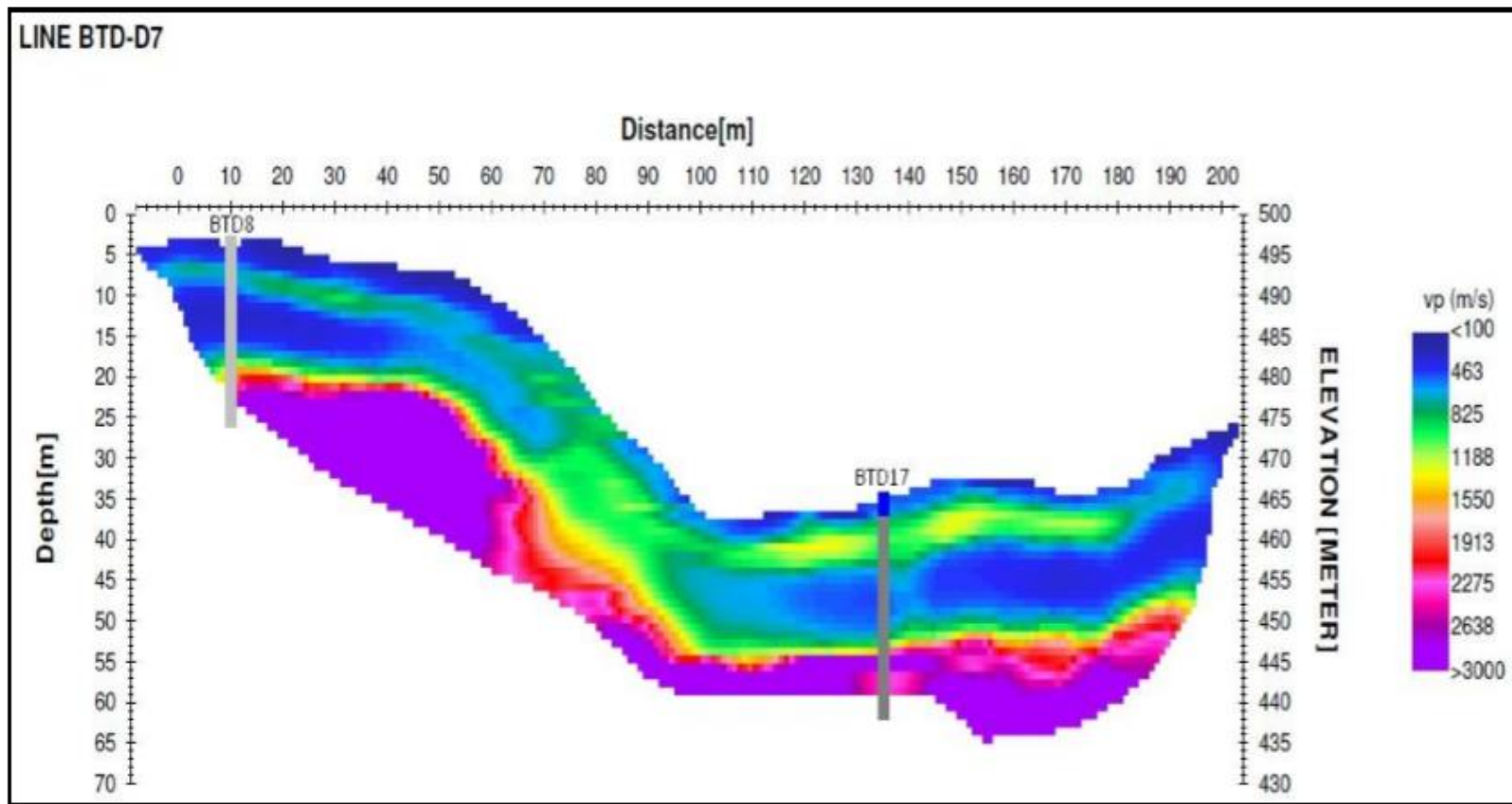

Gambar 12. Penampang seismik line BTD-D7 